\title{
NIÑOS ENTRE \\ FRONTERAS: MIGRACIÓN DE MENORES NO ACOMPAÑADOS EN EL MEDITERRÁNEO OCCIDENTAL
}

\author{
LILIANA SUÁREZ NAVAZ
}

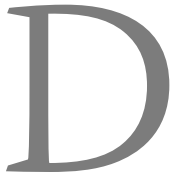

esde finales de los años noventa, los medios de comunicación españoles hacen eco de un nuevo tipo de migración: la de niños que cruzan el mar Mediterráneo con intención de «buscar la vida» en Europa. Hace apenas seis meses tuve la oportunidad de ver a estos menores en Tánger, ciudad fronteriza por excelencia, bajando al puerto para intentar dar el «salto» hasta España. ${ }^{1}$ En el puerto actúan en grupos, escondiéndose de la policía y observando el movimiento de camiones y barcos. En el momento apropiado, se cuelan por debajo de alguno de los muchos camiones o autobuses que, diariamente, pasan la frontera hacia Europa. Agarrados de los ejes, se esconden en los pequeños huecos por debajo de los transportes y aguantan varias horas hasta llegar a Algeciras, en el sur de España. Es un viaje muy peligroso, donde el niño arriesga su vida.

Apenas hace un mes hemos visto, sobrecogidos, la primera imagen de una patera

\footnotetext{
${ }^{1}$ Este artículo está basado en el trabajo de investigación encargado por el Servicio de Investigación de la Dirección General de Acción Social, del Menor y de la Familia, del Ministerio de Trabajo y Asuntos Sociales al Programa Migración y Multiculturalidad de la Universidad Autónoma de Madrid. El proyecto, dirigido por Carlos Giménez y coordinado por mí como investigadora principal, fue realizado por un equipo de investigación especializado en el tema. Cubrimos todas las comunidades autónomas donde hay más presencia de menores no acompañados, con estudios de caso a profundidad (Madrid, Andalucía, Canarias, Cataluña y las ciudades autónomas de Ceuta y Melilla). El estudio es, hasta la fecha, el más exhaustivo y ambicioso realizado en el Estado español y lamentamos que ciertas dificultades institucionales hayan impedido su publicación completa (para ver un resumen de la investigación, consultar Giménez y Suárez, 2001). En junio de 2003, como asesora académica de un proyecto de investigación sobre menores no acompañados de UNICEF y la Fundación Jaume Bofill, viajo a Tánger y tengo la oportunidad de visitar los barrios de origen de los menores, así como algunas de sus familias. Agradezco a la investigadora principal del proyecto en Tánger, Mercedes Jiménez, su generosidad al compartir conmigo las transcripciones de las entrevistas de los menores y sus familias en el proceso de preparación de este artículo, así como por su hospitalidad en Tánger.
} 
zodiac llena de jóvenes marroquíes. Es la primera vez que tantos niños usan este medio para cruzar la frontera. En la foto se les veía aterrados tras haber sido arrastrados por las corrientes del traicionero mar Mediterráneo, sabiendo que este arriesgado viaje sólo iba a conducirlos ahora hacia la expulsión y quizá de cabeza a las comisarías marroquíes.

No estamos ante hechos aislados, ante chicos especialmente aventureros que optan por seguir el camino de sus compatriotas hacia la riqueza de Europa. Estamos ante un nuevo tipo de migración, que sigue las trayectorias geográficas de las migraciones adultas, pero tiene su propia dinámica y naturaleza. En este breve artículo queremos ofrecer un panorama de la situación y de las características que nos hacen pensar en un nuevo sujeto migratorio, centrándonos en el caso de los menores no acompañados (MNA en lo sucesivo) ${ }^{2}$ que salen del norte de Marruecos. Una vez presentado el contexto que condiciona las pautas migratorias de estos menores, se presentarán sus características desde su origen y una tipología basada en nuestra investigación comparada en España (Madrid, Cataluña, Andalucía, Canarias y las ciudades fronterizas de Ceuta y Melilla). En la última sección analizaremos a los menores como parte de un tipo de migración internacional nuevo y específico, esperando que este caso pueda ser puesto en contexto para comenzar a realizar una labor comparativa, pendiente hoy en día.

\section{EL CONTEXTO MIGRATORIO Y NORMATIVO DE LOS MNA}

En el año 2000, el Observatorio de la Infancia del Ministerio de Trabajo y Asuntos Sociales convoca a un grupo de trabajo sobre MNA, en el que están presentes los encargados de las instituciones con responsabilidades en este fenómeno. ${ }^{3}$ A partir de estas reuniones se encarga a la Universidad Autónoma de Madrid una investigación sobre el fenómeno que nos ocupa en este ensayo, estudio en el que nos basamos aquí por no haberse realizado a nivel estatal ningún otro hasta la fecha. Los MNA en el Estado español son, mayoritariamente, niños y jóvenes marroquíes que han entrado en el país de forma irregular, habitualmente en los ejes de los camiones que cruzan la frontera. Aunque por ley tienen derecho a ser protegidos por el sistema de atención pública, muchos de ellos están en las calles. Su presencia generaba en aquel momento,

\footnotetext{
${ }^{2}$ El Consejo de la Unión Europea define a los MNA como «niños y adolescentes menores de 18 años nacionales de terceros países que se encuentran en el país receptor sin la protección de un familiar o adulto responsable que habitualmente se hace cargo de su cuidado ya sea legalmente o con arreglo a los usos y costumbres» (Resolución del Consejo de la Unión Europea del 26 de junio de 1997 relativa a menores no acompañados, nacionales de terceros países, 97/C221/03). Dependiendo de las Comunidades Autónomas, la denominación puede variar ligeramente: MENA (menores extranjeros no acompañados), MEINA (menores extranjeros indocumentados no acompañados) o MINIS (menores inmigrantes de vida independiente). En el contexto europeo, e incluso a nivel de Naciones Unidas, se ha optado también por la denominación de «menores separados» para enfatizar la separación como la problemática central.

${ }^{3}$ Además del Ministerio de Trabajo y Asuntos Sociales, está el Ministerio de Interior (los responsables de migración y de policía), el de Asuntos Exteriores, la Fiscalía General del Estado, algunos juzgados de menores, la Federación Española de Municipios y Provincias (FEMP), la Cruz Roja, la Plataforma de Organizaciones de la Infancia y las Comunidades Autónomas (CCAA).
} 
igual que ahora, una enorme alarma social: los pequeños delitos cometidos por estos menores tenían y tienen un eco desproporcionado en la prensa. A tenor de los vecinos, su edad los hacía impunes; a tenor de los profesionales y los políticos, los menores constituían, sin duda, un fenómeno difícil de manejar. Uno de los objetivos que nos marcamos en aquel trabajo pionero era situar el fenómeno en su justo término, evitando el sobredimensionamiento que adquiría para la opinión pública, amén del racismo y rechazo popular que su presencia generaba.

Frente a otros países de la Unión Europea, lo que distingue a España, y otros países europeos de «nuevas migraciones», es que en ninguna medida estamos hablando de niños que huyen de conflictos, esto es, solicitantes de asilo y refugio. Aunque la pobreza, la violencia estructural y la exclusión social son, sin duda, fenómenos de los que las personas huyen, y más en concreto los niños de los que hablamos, mantenemos como operativa la distinción entre emigrantes económicos y refugiados. Estos niños son, en cierta medida, unos migrantes más, que buscan mejorar su vida, abrirse un futuro que no es fácil vislumbrar en Marruecos. Sus objetivos, según todos los estudios y los informes de las ONG que trabajan para ellos, son «papeles y trabajo».

Los MNA son percibidos como un «problema» y creemos que esto es parte de las razones de su rebeldía. Los menores son personas que han nacido y crecido en un contexto de pobreza y exclusión que les niega posibilidades y, en algunos casos, cariño y reconocimiento. Su lucha por la supervivencia, la autonomía y la dignidad les dirige hacia la emigración, donde son percibidos como niños «difíciles» y costosos para el erario público. El sistema de acogida y atención español no contaba con ellos, además de que hay síntomas de desbordamiento y frustración por todas las partes por donde pasan. No obstante, no se trata de un «problema» cuantitativo sino cualitativo. Nuestra estimación cuantitativa en el año 2000, sujeta a todo tipo de inexactitudes e imprecisiones debido al deficiente sistema de registro, eran unos 1,500 muchachos en toda España. Hoy en día, el Observatorio de la Infancia habla de 6,000, pero de nuevo, sin precisar las fuentes, podemos muy fácilmente estar en otro de los socorridos intentos de multiplicar los números en función de algunos de los objetivos políticos, que ya en otras ocasiones se han develado.

Una de las razones más importantes, por la cual los MNA son percibidos como un problema, es que ellos encarnan las profundas contradicciones del sistema normativo que rige la vida del niño en España: ${ }^{4}$ mientras que, como niño, el MNA tiene todos los derechos reconocidos por nuestra normativa, como extranjero indocumentado el

\footnotetext{
${ }^{4}$ España ratifica, en diciembre de 1990, la Convención de Derechos del Niño (ONU, 20 de noviembre de 1989). A nivel nacional, la constitución ratifica, en su artículo 39, el derecho de los niños a la protección prevista en los acuerdos internacionales y se guía por la Ley Orgánica 1/1996 del 15 de enero de Protección Jurídica del Menor, conocida como la Ley del Menor. Esta ley obliga a hacer primar el derecho superior del niño sobre cualquier interés legítimo que pudiera concurrir y se refiere, en el artículo 10, puntos 3 y 4, a los niños extranjeros, reconociendo el derecho de los menores extranjeros que se encuentren en situación de riesgo, o bajo tutela o guarda de la administración pública competente, la asistencia sanitaria, educación y demás servicios públicos aún y cuando no residan legalmente en España, además de reconocer el derecho del menor a ser documentado. Por su condición de extranjeros, los MNA están regulados por la Ley Orgánica 4/200 del 11 de enero, sobre derechos y libertades de los extranjeros en España y su integración social, en su redacción dada por la Ley Orgánica 8/2000 de reforma de la Ley Orgánica 4/2000 (artículo 35).
} 
interés primordial es su expulsión. Entre estos dos marcos normativos, el niño y el joven se mueven como pez en el agua. Reclama sus derechos, pero sabe, a la vez, que está en peligro inminente de expulsión. Su peligroso juego de evasión y petición de santuario se basa en buscar los resquicios de este doble juego legal y estatal: protección y expulsión. ${ }^{5}$ Pero esto lo veremos al final del artículo.

\section{RASGOS SOCIOLÓGICOS \\ DE LOS MNA EN MARRUECOS}

De forma muy resumida podemos decir que, al hablar de MNA en España, nos referimos a niños y jóvenes varones marroquíes que tienen desde 10 hasta 18 años. A grandes rasgos, hablamos de niños que han abandonado, o apenas han seguido, uno o dos cursos en el sistema educativo y lo han dejado, en gran parte, por la violencia que allí encuentran y la falta de expectativas. Niños que pertenecen, en su gran mayoría, a familias pobres o muy pobres, que en muchas ocasiones han emigrado a la ciudad y se han instalado en un barrio de aluvión, como el tangerino Beni Makada. La mayoría de estas familias han tenido muchos hijos y apenas pueden mantenerlos. Han sufrido los efectos de la desindustrialización, no tienen formación y no encuentran, en su contexto, recursos suficientes para la supervivencia de todos sus miembros.

Entre los MNA apenas hay niñas, hablamos de un «juego» o de una «aventura» para «hombres». ${ }^{6}$ Más aún, en la cultura árabe-musulmana en la que se crían estos chicos, se espera del hombre que cumpla con el rol proveedor, mientras que la mujer se casará y su futuro no será responsabilidad de la familia biológica, sino de su marido y de su familia política. ${ }^{7}$ Los hombres, además, tienen que ser «duros», asumir responsabilidades, mantener el honor y defender la integridad de los suyos. Los niños, a las puertas de su adolescencia, la mayoría de ellos, esperan acelerar su rito de paso hacia la sociedad adulta a través de la emigración. Pero no se trata sólo de un rito de iniciación a la edad adulta plenamente efectivo. Los niños comienzan a pensar en esta migración a partir de los diez años, según confirman las entrevistas realizadas. Todos

\footnotetext{
${ }^{5}$ En 2002, diferentes organizaciones de reconocido prestigio, como el Defensor del Pueblo Español, Human Rights Watch, Amnistía Internacional o el Comité de Derechos del Niño, denunciaban la existencia de expulsiones sumarias de MNA sin respeto de los derechos fundamentales reconocidos en la normativa. La política del gobierno y de las Comunidades Autónomas está dando prioridad a la reagrupación familiar de los menores, pero éstas no se han dado respetando las garantías que estipula la legislación nacional e internacional, siendo más bien reconocidas como expulsiones encubiertas (ver nota 18).

${ }^{6}$ Sabemos que hay niñas que también se embarcan en un proyecto migratorio solas, pero no usan los canales de entrada tan característicos de los chicos (los ejes de los camiones), ni sus ocupaciones, clandestinas por supuesto, las sacan a luz (servicio doméstico o prostitución). En los últimos años es destacable la presencia de niñas en la prostitución callejera, sobre todo nigerianas. Este fenómeno no ha sido aún abordado ni por las autoridades públicas, que lo toleran, ni por las asociaciones dedicadas a estos temas, por la extremada dificultad en el acceso a estas niñas, «protegidas» por redes de tráfico que dicen mantener los usos y costumbres del país de origen.

${ }^{7}$ Esta ideología de género, así como la traducción de la misma en la casi completa segmentación sexual del trabajo y los espacios públicos, se mantiene a pesar del profundo impacto de los fenómenos de feminización de la pobreza en Marruecos.
} 
quieren «mejorar su situación»o, como ellos dicen, «buscarse la vida». Escuchemos a los propios niños responder a la pregunta de por qué quieren emigrar: ${ }^{8}$

»Porque en este país no hay nada y quiero mejorar mi situación (I.H., 17 años). »Mi hermano me presionaba y me insultaba para que buscara un trabajo y por eso empecé a bajar al puerto [...], mi madre sabía que quería irme, me rogaba que me quedara y yo le suplicaba que dejara irme, y cuando se cansó me bendijo y me dijo que hiciera lo que quisiera (H., 14 años).

»Quiero regularizar mi situación y conseguir mis papeles (A.A., 15 años).

»Quería ir a España ya que ahí te permiten estudiar e ir al colegio, reeducarte [...] [quiero ir porque] hay muchas cosas buenas. Te llevan a un colegio y te arreglan los papeles para que puedas pasear tranquilamente, y después puedes trabajar y comprarte una casa aquí (A., 13 años).

El entorno urbano precarizado y la falta de horizonte en un país como Marruecos condiciona, fuertemente, las expectativas de estos menores. Barrios como Beni Makada son producto de una urbanización acelerada y del chabolismo que ha acompañado estos procesos. En general, los padres de estos niños tienen condiciones de subempleo y, aunque los menores hablan con cariño de sus progenitores (con excepción de los casos de abuso, que también encontramos), el concepto de protección y supervisión de los niños no es el mismo que en el sector de clase media occidental. En el núcleo familiar encontramos de 5 a 10 hermanos; los problemas y las angustias de los padres las viven los niños, desde pequeños, en sus casas. Las condiciones de las casas, donde dos habitaciones para todos es lo más corriente, hace que los muchachos tiendan a salir a la calle y pasar muchas horas fuera, jugando con sus amigos sin la supervisión de adultos y sometidos a las reglas y jerarquías de este ámbito.

Dado que se espera de los chicos su colaboración en los gastos familiares en cuanto dejan la escuela (que suele ser muy pronto), los menores se integran en el entorno laboral rápidamente. En algunas ocasiones ejercen de aprendices y no son respetados como personas ni como trabajadores, reciben un sueldo simbólico por largas horas de trabajo. ${ }^{9}$ Es también muy común, y en ocasiones la antesala de su conversión en niños de la calle, que se dediquen a todo tipo de actividades en la calle, como la mendicidad y el acoso a los turistas.

En una reunión realizada en Marruecos, en junio de 2003, sobre los MNA y el deseo contagioso de emigrar entre niños de todo el país, varios expertos hacían hincapié en la necesidad de restaurar el sistema de autoridad ante niños que no eran controlados por sus familias, que se rebelaban y no atendían a los consejos de sus padres. Aunque, ciertamente encontramos casos en los que los menores emigran a espaldas de sus familias, no es éste el caso más generalizado y, de cualquier manera, no necesariamente la solución es volver a los esquemas autoritarios del pasado, porque, probablemente, ya

\footnotetext{
${ }^{8}$ Estos testimonios son parte de las entrevistas realizadas por el equipo coordinado por Mercedes Jiménez en Tánger, en la investigación de UNICEF «Análisis de los procesos migratorios de los menores marroquíes en España».

${ }^{9}$ Esta situación laboral es señalada por algunos menores y sus familias como causa directa del proyecto migratorio.
} 
no existen las condiciones para que se mantenga o reproduzca. En muchas ocasiones, los padres (o uno de ellos) son plenamente conscientes de los deseos de sus hijos. No lo aprueban explícitamente, pero reconocen que sería una gran ayuda que el menor trajera algo (más) de dinero a casa o que, por lo menos, fuera una boca menos que alimentar si consiguiera emigrar a Europa.

Después de todo, cuando hablamos de estos niños, no podemos olvidar el enorme empuje migratorio hacia España y Europa de que son testigos. Familiares y vecinos emigrantes vuelven, en verano, haciendo alarde de sus conquistas económicas, adquiriendo un estatus social impensable para quienes no consiguen emigrar. Los menores están condicionados por estos procesos migratorios pero, como veremos más abajo, no hacen uso directamente de las redes transnacionales establecidas por los adultos, sino que desarrollan las suyas propias y, en este sentido, son un nuevo sujeto migratorio.

Como expondremos en la tipología que presentamos en la siguiente sección, la gran mayoría de MNA no son «niños de la calle», esto es, aquellos que han hecho de la vía pública su hábitat natural de vida, con poco contacto familiar. Sin embargo, su trayectoria vital - poca escuela, mucha calle, poco dinero en casa- hace de estos niños un grupo de alto riesgo, expuestos al falso imaginario de «El Dorado». Esta pulsión por emigrar, que encontramos en gran parte de Marruecos, se hace más acuciante en el norte y, especialmente, en zonas fronterizas como Tánger o Tetuán. La cercanía hace este objetivo migratorio más factible y son muchos los menores que, cada vez más, se trasladan a estas ciudades y esperan el momento propicio para hacer viable este sueño de cruzar el estrecho.

\section{TiPOLOGÍAS DE MNA}

Uno de los intereses de nuestro trabajo era superar la tendencia a generalizar sobre los MNA y a basarse en estereotipos poco sistemáticos, así como apuntar hacia la conveniencia de crear una tipología unificada, misma que sirviera para el diseño de políticas adecuadas a sus necesidades.

La información disponible es, de manera fundamental, referente a MNA marroquíes, y apenas hay información de menores de otros lugares dado que no suelen acceder al sistema de protección. Tampoco hablamos aquí de hijos de inmigrantes, aunque algunos corren el riesgo de convertirse en MNA en España, dada la precaria situación económica de los padres, la falta de atención de los mismos por problemas en la familia o por el escaso tiempo que puedan tener para estar cerca de sus hijos. Es por ello que estamos impulsando investigaciones que incluyan a los menores de segunda generación, quienes, por encontrarse en situación de riesgo y clara desprotección «de facto», puedan llegar a tener situaciones similares a las de los MNA.

Los criterios más relevantes para establecer diferencias entre los MNA son la situación sociofamiliar de origen, la motivación y expectativas de su proyecto migratorio y el tipo de vida de los niños, tanto en el lugar de origen como en el de destino. Otros criterios importantes, como el lugar de origen y la edad, no son incluidos en nuestra propuesta. Tampoco incluimos la nacionalidad, porque la información disponible refiere sólo a los MNA marroquíes (y, con cierta importancia, argelinos que comparten con ellos los rasgos culturales básicos, aunque la situación sociopolítica difiera). La edad es un criterio generalmente escogido por las instituciones para diferenciar el tipo de pro- 
gramas en los que el menor es incorporado. Sin embargo, no hemos podido constatar que sea la edad un criterio unificable para todos los menores, puesto que tiene mayor incidencia el tipo de desarrollo personal-familiar que haya tenido el menor.

La tipología, finalmente propuesta, distingue los tres grupos de MNA, que denominamos para efectos de claridad grupos 1, 2 y 3 . El grupo mayoritario es el 1 . No obstante, y éste es quizá uno de los resultados más preocupantes del estudio, consideramos que las condiciones de vida de estos menores (muchos de ellos indocumentados y, por tanto, sin posibilidades de trabajar de forma legal en nuestro país, unido a la acentuada prioridad que estos menores dan a su autonomía personal y a la vida en la calle) hacen que el paso de uno a otro grupo pueda ser más fácil de lo que inicialmente las características sociológicas de inicio pudieran sugerir.

\section{GRUPO 1: MENORES MigRANTES}

Son MNA con vínculos familiares, proyecto migratorio claro y hábitos más o menos asentados de vida en la calle (en lugar de origen o destino). No son «chicos de la calle».

- Estos menores provienen de un ambiente familiar más o menos estable, pasan gran parte de su tiempo en la calle, pero no hacen de ésta un medio de vida (Informe Andalucía). Su vida en la calle corresponde más al modo de vida general en las ciudades y pueblos donde viven que a una opción o estrategia personal.

- Suelen tener un proyecto migratorio claro. Sus necesidades, a tenor de lo que ellos y los profesionales que trabajan con ellos nos transmiten, son fundamentalmente «papeles, trabajo e información». En ocasiones ha sido la propia familia la que ha potenciado este proyecto migratorio.

- En general son percibidos como «poco problemáticos», aunque sus expectativas migratorias (encontrar papeles y trabajo) no se adecúan, en general, a los programas educativos que se ofrecen en el sistema de acogida. Como dato interesante destaca el hecho de que los menores de 16 años suelen mentir respecto a su edad, para verse incluidos en programas más dirigidos hacia la inserción sociolaboral y para evitar la reagrupación familiar, en general priorizada para cualquier menor de 16 años.

- Mantienen vínculos con su familia de origen. Algunos se limitan al teléfono, pero otros viajan, con cierta frecuencia, a Marruecos a visitar a sus familias en eventos especialmente significativos, como Ramadán o la Fiesta del Cordero.

- A pesar de mantener vínculos, más o menos estables, con su familia de origen, no desean iniciar el retorno de forma voluntaria.

- Conocen la legislación y hacen uso del sistema de protección y acogida al menor para maximizar los esfuerzos y así lograr sus objetivos.

- No sabemos el porcentaje que están documentados y/o tutelados, pero sabemos que los usos y costumbres de las diferentes CCAA y ONG varían, de forma que puede haber casos que logren sus permisos de residencia y/o trabajo en pocos meses, otros que sean procesos de 
más de un año y otros más que, como norma, no tramiten este tipo de documentación.

- A nivel psicológico tienen más madurez que los niños de su edad en situación comparable por las responsabilidades adquiridas en el núcleo doméstico desde temprano en sus vidas. Éste es un elemento importante en su rechazo a los centros de protección, que resultan demasiado paternalistas y tratan al menor como un niño y no como una persona con objetivos claros y responsabilidades tempranas, sobrevenidas por la situación económica de sus familias.

- Resienten el rechazo racista en España y la imagen que otros menores marroquíes, más conflictivos, dan.

- Si pasan demasiado tiempo en la calle, sin un trabajo mediante el cual puedan generar ingresos y mandar remesas, pudieran perder los vínculos familiares y entrar en dinámicas más propias del grupo 2 ó 3.

- El tipo de actuaciones ideales, con este grupo de menores, debería centrarse en mantener los vínculos familiares, incluirlos en proyectos educativos integrales y personalizados que incluyen el seguimiento cercano de la trayectoria por parte de educadores especializados, realizar proyectos de reinserción sociolaboral en los lugares de origen o destino, potenciar créditos a sus familias, documentarlos.

GRUPO 2: MENORES DE LA CALLE CON ITINERANCIA TRANSNACIONAL MNA sin vínculos familiares positivos, en general, sin proyecto migratorio claro y con una trayectoria más o menos temprana de «niños de la calle» (en lugares de origen o destino).

- MNA procedentes de familias altamente desestructuradas y marginales. La incidencia de separación conyugal, violencia doméstica, agresión infantil, ninguneo y desprecio es alta, produciendo una falta de confianza en los referentes adultos. En varias ocasiones se han visto obligados, por su propia familia, a vivir en la calle y mendigar o robar para cumplir con las exigencias que se les imponían.

- Su escolarización es escasa (escuelas coránicas, primeros niveles de la educación primaria). El tipo de educación recibida (autoritaria y violenta) les hace rechazarla.

- El ambiente familiar produjo una ruptura dramática que les lleva a ser considerados, propiamente, «niños de la calle», haciendo de ésta una forma de vida.

- La vida en la calle les ha hecho encontrarse con situaciones violentas, a las que se han tenido que enfrentar solos, con apenas la ayuda de otros niños que comparten esa situación.

- Han desarrollado comportamientos agresivos y prácticas de adicción a sustancias estupefacientes. En ocasiones se les denomina «niños del pegamento» o «niños de la cola».

- No tienen un proyecto migratorio claro, actúan a impulsos, sin noción clara de futuro ni proyecto vital. 
- Han desarrollado prácticas evasivas. Se esconden en grutas y prefieren evadir el control policial, trasladándose a las zonas más marginales o viviendo de noche.

- No están capacitados para encontrar trabajos estables. Su falta de hábitos les hace difícil concentrarse en un trabajo u objetivo, prefiriendo «buscarse la vida» diariamente.

- Rechazan, de forma visceral, los centros de acogida, y suelen fugarse inmediatamente si no se les ofrece contrapartidas claras e inmediatas. Sus valores más preciados son la libertad y la independencia.

- A nivel psicológico presentan claros rasgos de trauma, lo que les hace adoptar una actitud aparentemente distante y fría en cuanto a sus relaciones sociales. Es una actitud defensiva, arrogante e intolerante.

- Están acostumbrados a defenderse de los peligros de la calle. Usan armas blancas y en ocasiones armas de fuego, si tienen acceso a ellas. La vida es puesta en riesgo sin que exista clara conciencia de ello.

- El tipo de actuaciones ideales, con este grupo de menores, debería centrarse en una atención personalizada en familias profesionales o centros pequeños (Capdevilla, 2000), así como un sistema de atención permanente con educadores de calle y mediadores culturales. Si los MNA rechazan toda intervención, «el trabajo ha de limitarse al de aproximación, acogida y reducción de daños eventuales que se pueden derivar de la situación de desamparo del menor y, en concreto, de los riesgos que comporta la calle (prostitución, delincuencia, toxicomanías)» (Informe Cataluña).

GRUPO 3: MENORES CON GRAVES PROBLEMÁtiCAS PERSONALES MNA con antecedentes delictivos, comportamientos agresivos graves o problemas serios de salud (incluídos un porcentaje de transtornos mentales). Son también «niños de la calle».

- Estos niños son una minoría, pero crean gran alarma social. Para la descripción de sus rasgos idiosincráticos nos inspiramos en el artículo presentado por Capdevilla, en el II Congreso de Migraciones en España, para desarrollar con detalle este tipo de MNA.

- En muchos casos se trata de un perfil semejante al grupo 2, pero agravado. El tiempo en la calle, dramáticas experiencias y circunstancias personales los han empujado a un camino sin retorno.

- Existe un porcentaje elevado de MNA captados por mafias diversas (prostitución, estupefacientes). Son usados como correos de droga (denominados «mochileros») y algunos se dedican a la prostitución, protegidos por proxenetas.

- Por sus antecedentes delictivos, han pasado por prisiones en el país de origen o por centros cerrados de reforma.

- Entran a formar parte de bandas de menores y jóvenes adultos, que imponen su ley en la calle. En este ambiente se someten a las reglas del grupo y a la división del trabajo establecido. Según Capdevilla 
«viven principalmente del robo a los turistas. Se quedan el dinero y cambian las joyas a los peristas y los pasaportes y tarjetas de crédito a las mafias a cambio de ropa, calzado deportivo de marca, walkmans, o incluso a veces golosinas» (Capdevilla, 2000).

- Están acostumbrados al dinero fácil; no es sencillo que abandonen sus prácticas delictivas para incorporarse a un trabajo menos remunerado y unas pautas normalizadas de convivencia.

- No respetan a los adultos y se mofan de los valores y formas de control social, consensuados o impuestos, en el país de origen y destino.

- Para aquellos que sufren transtornos sanitarios físicos y mentales graves, se impone «tratamiento psiquiátrico y médico y tratamientos de continuidad, medicación específica y/o periodos de aislamiento hasta que su enfermedad esté diagnosticada o deje de ser un problema de salud pública» (Capdevilla, 2000).

- Para aquellos con conductas especialmente agresivas y delictivas se imponen medidas especializadas: reformatorios, atención psicológica, atención médica.

\section{UN NUEVO SUJETO MIGRATORIO}

Cuando participé en la Conferencia Internacional sobre la Problemática de Repatriación de Menores Migrantes no Acompañados, que tuvo lugar en Tetuán en junio de 2003, la inmediatez y dureza del fenómeno que tratábamos hacía que muchos de los participantes se centraran en cuestiones locales o en las relaciones políticas entre Marruecos y España, siempre tensas y difíciles. No queriendo quitar importancia a los contextos migratorios y políticos del fenómeno que intentábamos conocer, quise, sin embargo, poner énfasis en los rasgos comunes que la migración de los niños y jóvenes marroquíes tenía con otros fenómenos en distintos rincones del mundo. La intervención abrió todo un panorama comparativo que está por realizarse. Es esta temática la que quisiera abordar en esta última sección.

En primer lugar, es constatable en todo el mundo, y se refleja en diversos informes de Naciones Unidas y UNICEF, que estamos enfrentándonos a una vivencia de la juventud e infancia desgarradora, opuesta a la idea burguesa de infancia en la que los niños y jóvenes viven la primera etapa de sus vidas, protegidos por adultos responsables, que priman los intereses del menor y que potencian su educación y desarrollo. La existencia de niños desprotegidos, que son arrojados a las inclemencias de la vida adulta prematuramente, no es nueva. Desde hace más de dos décadas se vienen proponiendo expresiones que intentan atrapar la esencia de la vida de estos menores: «niños sin infancia», «menores abandonados», «jóvenes sin futuro», «desechables», «sicarios», «niños de la calle». Se constata el aumento de estos niños en medio mundo, condenados a vivir desde muy pronto situaciones de soledad, violencia y pobreza. No es un tipo de pobreza semejante al que se podía vivir en el ámbito rural, dentro de grupos corporativos que protegían a sus miembros. Los niños y jóvenes, sujetos a procesos de exclusión sangrantes en el ámbito urbano, buscan apoyo y grupo de socialización en sus iguales. Ante la exclusión, los chavales se juntan en grupos y se defienden con violencia de una situación de desprotección y abandono. 
Los MNA, objeto de nuestro estudio, comparten esta vivencia de muchos niños «sin infancia» a lo largo y ancho del mundo. Todos son víctimas de los efectos dramáticos de los planes de ajuste estructural, de la proletarización acelerada de una población de origen eminentemente rural y de las nuevas bolsas de miseria de las grandes ciudades, donde se rompen los vínculos de la familia extensa, tan importantes para hacer frente a las dificultades de la vida y para socializar a los menores en los valores sociales fundamentales. En cierta medida, esto era lo que echaban de menos personas como la psiquiatra infantil Amina Bargach, a la que antes me refería, cuando aludía a la necesidad de autoridad y rutina en las familias de donde provenían estos menores.

Sin embargo, pienso que, en general, se mantiene una percepción muy negativa de la migración de los menores, la cual no permite destacar el carácter innovador y particular de estas migraciones, y de los propios menores como constructores activos de estrategias de supervivencia efectivas. En parte sucede que esta migración se asimila a los flujos migratorios más amplios que unen España (y Europa) con Marruecos (y África), destacando, en el caso de los niños y jóvenes, su vulnerabilidad y la patente violación de los derechos que los acuerdos internacionales y la normativa nacional les garantizan. Aunque es evidente la necesidad de denuncia y apoyo a estos menores en España para que sus derechos sean salvaguardados, creo que es errónea su representación mayoritaria como meras víctimas del sistema sociocultural. Si bien es cierto que esta situación de nuestros niños no es en ninguna medida deseable, quisiera defender la idea de que estos menores están construyendo alternativas propias a la situación en la que se ven atrapados.

Los MNA, con quienes hemos hablado, están haciendo uso de sus propios recursos a la hora de emigrar, no sólo en las estrategias de entrada, sino también en las redes sociales que la sustentan, en gran medida independientes del control de los adultos. A esto añadimos la extraordinaria movilidad y el dinamismo de las redes de información y apoyo entre los menores, que si bien resultan un obstáculo para los investigadores, profesionales de atención juvenil y políticos, son parte de las estrategias de resistencia al control estatal, social y familiar que se cierne sobre su futuro.

En las reuniones de trabajo, con el equipo de investigación de Tánger y Barcelona, resultó evidente la importancia socioafectiva que los niños y jóvenes ponían en su pandilla. No cabía ninguna duda de que era en este entorno en el que se comenzaba a acariciar la idea de la emigración, desde los 10 a los 14 años, y se comenzaban a hacer las primeras incursiones en el puerto. Los niños que se están entrevistando utilizan estas redes de iguales para emigrar, mucho más que las de vecinos o parientes. Podemos hablar, por tanto, de recursos autónomos para su emigración que no implican dinero sino valentía, capacidad de poner en riesgo la vida e información suficiente. ${ }^{10}$

Los niños que responden a las preguntas del estudio en Tánger se refieren, constantemente, a «sus amigos» y su importancia para el éxito del proyecto migratorio. También hacen referencia a la enorme competitividad que se establece entre las diferentes pandillas, así como la existencia de «soplones» o niños que aparentan ser uno más y son instrumentos de la policía. Los chavales inician este proyecto migratorio juntos, y aunque las circunstancias, la suerte y las fronteras les separen (lo cual

${ }^{10}$ Aunque, ciertamente, las últimas imágenes de los niños en las pateras nos hagan pensar en un viaje organizado por las mafias de tráfico de personas. 
es lo más corriente), saben, con bastante precisión, dónde están sus amigos y cómo se han «buscado la vida».

Pero esta red de relaciones es múltiple y está altamente desterritorializada (Glick Schiller et al., 1994). Los menores no sólo mantienen las amistades de sus pandillas de origen, sino que el tipo de vida en la calle hace que vayan forjando otras relaciones de apoyo e, incluso, amistad en el curso de su itinerario migratorio. Los menores acaparan con celo la información que se transmite en la red de sus amigos sobre qué centros son más adecuados, qué hay que decir en las declaraciones ante la policía, dónde se puede ganar dinero fácil sin excesivos compromisos. Dependiendo de sus objetivos y sus necesidades coyunturales, los menores decidirán acogerse a la protección oficial y entrar en un centro de atención al menor, o escaparse y ganar dinero aunque sea sin los correspondientes permisos.

Aún necesitamos mucha investigación, menos prejuicios y menos actitudes paternalistas, para poder entender las dinámicas de la migración infantil y juvenil en Europa. Aparentemente se produce una yuxtaposición de intereses personales del joven con los intereses de su familia, pero es necesario hacer una labor de seguimiento de las trayectorias de estos menores. Es seguro que, en el contexto del que parten estos chavales, resulta moralmente inaceptable para ellos afirmar que no quieren tener nada que ver con su familia. ${ }^{11}$ En especial el rol y la presencia de la madre son notorios en las narrativas de los menores, y es cierto que serán ellas las que más valoren los esfuerzos de sus hijos por salir adelante y echar una mano en casa. ${ }^{12}$

La ruptura generacional y el choque de intereses se muestran de forma evidente en las entrevistas con las familias; las madres o padres se lamentan de las «malas compañías» y de su incapacidad para vigilar y controlar a sus hijos. Pero para los menores parte del interés de las pandillas radica en que les permiten escapar del control de su familia y acceder a proyectos semiautónomos, en los que se incluye una cierta noción de aventura, riesgo e independencia. Creo que esa es una de las razones por las cuales los itinerarios de los MNA no responden a esa lógica lineal que preferirían sus padres en Marruecos y sus educadores en España. ${ }^{13}$ El menor incluye periodos en los que - por decirlo de forma popular: «asienta la cabeza»— busca trabajo estable o se incorpora en los programas educativos ofertados por los centros de acogida. Pero,

\footnotetext{
${ }^{11}$ Hemos visto casos en los que la violencia familiar es tan fuerte que en efecto el menor ha optado por la separación radical de sus intereses, pero en estos casos parece, más bien, una respuesta de supervivencia, más que una opción personal.

${ }^{12}$ Esta relación materno-filial corresponde claramente a la alusión de Amina Bargarch de que el niño emigrante se convierte en el líder de la familia. No parece que los padres tengan en tanta estima la aportación del menor, sino que en ocasiones puede representar una amenaza a su autoridad, que tradicionalmente estuvo vinculada a su rol como proveedor, y que ha entrado en crisis como efecto de la desindustrialización y la nueva pobreza urbana.

${ }^{13}$ Acuerdo entre el Reino de Marruecos y el Estado Español de la repatriación de menores migrantes, 2003. Aparte de este acuerdo, cuyos efectos aún están valorando los expertos, se han llevado a cabo políticas de expulsión encubiertas como las denunciadas por los organismos internacionales mencionados en la nota 5. En el mes de marzo de 2003, varias asociaciones de Madrid presentaron tres denuncias a la Fiscalía del Tribunal Superior de Justicia, todas ellas contra el delegado de gobierno en Madrid y la directora gerente del Instituto Madrileño del Menor y la Familia por la repatriación, a principios de 2003, de cuatro menores de origen magrebía en condiciones que, supuestamente, habían puesto en peligro la vida de los menores y vulnerado su integridad física y moral.
} 
para frustración de sus educadores y sus padres, el menor rompe en varias ocasiones con esta trayectoria «integradora», busca otros espacios más lúdicos y opta, temporalmente, por recursos económicos más cuestionables.

Así, el discurso se mantiene, todavía, claramente a favor del mantenimiento de los vínculos familiares, de la búsqueda de una opción laboral estable, de la regularización y de la integración en la sociedad de acogida. Aunque es cierto que esto depende de que el menor haya conseguido, en su vida en la calle, preservarse de ciertos peligros obvios y no caer, por así decirlo, en las tipologías del tipo 2 y, sobre todo, en la 3. En estos casos prevalecen, ya de forma absoluta, las lógicas marginales y juveniles; la desconfianza ante el Estado y los adultos es la tónica que prevalece. Como dijimos en 2000, creemos que aún estamos a tiempo de diseñar proyectos de investigación realistas y no dirigistas, de delinear proyectos de intervención que respeten la identidad de los menores, rescaten la valía de sus redes sociales y puedan establecer canales de diálogo, antes del deterioro que señalan ciertos estudios. La agresiva política de retorno, establecida por los departamentos ministeriales responsables en los Estados hispano-marroquíes, tiene un efecto negativo en los menores, que intentan evadir, en lo posible, los cauces oficiales por miedo a la repatriación.

Quisiéramos terminar redundando en la denuncia de las malas prácticas que los Estados marroquí y español mantienen con estos menores y la poca efectividad que tienen. Por ejemplo, de las 32 expulsiones documentadas por las autoridades de Melilla, todos habían regresado si no el mismo día, en dos o tres días como máximo. En junio de 2003 tuve la oportunidad de entrevistar a uno de los menores, objeto de las devoluciones denunciadas por varias ONG (ver nota 13). La familia sabía que estaba pendiente de poder volver a cruzar a Ceuta. No les importaba ni a él ni a sus padres el peligro de las palizas que podría recibir o el mayor riesgo: morir en el intento. Él estaba al tanto de sus compañeros en Madrid o Barcelona y nos puso al día de las últimas noticias sobre ellos. La madre, además, no censuraba su intención de marchar, puesto que entre el padre y ella no eran capaces de sacar adelante a la familia. Este niño, como muchos otros, necesita saber que esa posibilidad está presente. Y es necesario preservar ese derecho a emigrar, como una alternativa al futuro poco claro que les depara su entorno en Marruecos y, en la medida de las posibilidades, mantener el vínculo moral del menor con su familia. Este vínculo se revaloriza con la emigración, no a pesar de ella, y se rompe con el retorno forzado que sirve como moneda de cambio en la tensa negociación de ambos Estados.

\section{REFERENCIAS}

Capdevilla, Manel (2000), «Los menores extranjeros indocumentados no acompañados (MEINA): exigencia de respuestas», en II Congreso Migraciones en Espa$\tilde{n} a$, Madrid.

Giménez Romero, Carlos y Liliana Suárez Navaz (2000), «Menores no Acompañados que han entrado en territorio español sin representación legal», en Informe de investigación (3 vols.).

(2001), «Menores no Acompañados. Síntesis de una Investigación», en Menores Extranjeros no Acompañados, Unión de Asociaciones Familiares, Madrid. 
Human Rights Watch (2002), Callejón sin Salida: Abusos cometidos por las autoridades españolas y marroquies contra niños migrantes, vol. 14, núm. 4 (D)-mayo.

JimÉnez, Mercedes (2003), Buscarse la Vida: Análisis transnacional de los procesos migratorios de los menores de origen marroquí en Andalucía, Editorial SM, Madrid.

Plataforma de Organizaciones de Infancia (2003), Informe sobre la situación de los menores de origen extranjero en la Comunidad de Madrid. Visita de la Relatora Especial de las Naciones Unidas para los Derechos de los Migrantes, 17 de septiembre.

Quiroga, Violeta (2003), Els Petits Harraga. Menors immigrants irregulars no acompanyats d'origen marroqui a Catalunya, tesis doctoral, Universitat Rovira i Virgili, Departament D’Antropologia Social, Filosofía i Treball Social, julio. 